\title{
Differential regulation of AKT1 contributes to survival and proliferation in hepatocellular carcinoma cells by mediating Notch1 expression
}

\author{
JING CHEN ${ }^{1}$, JUN LIANG ${ }^{2}$, SHIHAI LIU ${ }^{3}$, SHANAI SONG ${ }^{1}$, WENXUAN GUO ${ }^{1}$ and FANGZHEN SHEN ${ }^{1}$ \\ ${ }^{1}$ Department of Oncology, Affiliated Hospital of Qingdao University, Qingdao, Shandong 266003; \\ ${ }^{2}$ Department of Oncology, International Cancer Hospital of Beijing University, Beijing 100000; \\ ${ }^{3}$ Central Laboratory, Affiliated Hospital of Qingdao University, Qingdao, Shandong 266003, P.R. China
}

Received June 17, 2016; Accepted November 10, 2017

DOI: $10.3892 / \mathrm{ol} .2018 .8193$

\begin{abstract}
The RAC serine/threonine-protein kinase (AKT) family of serine/threonine protein kinases, particularly the AKT1 isoform, has been identified abnormally expressed in hepatocellular carcinoma (HCC) cells, and is highly associated with cell behavior, including proliferation, survival, metabolism, and tumorigenesis. However, the specific mechanism by which AKT1 elicits these effects requires further study. The purpose of the present study was to reveal the effects of AKT1 on the survival and proliferation of HCC cells, and to investigate the mechanisms involved. Western blotting and reverse transcription-quantitative polymerase chain reaction (RT-qPCR) to evaluate the expression levels of AKT1 in HCC SMMC-7721 cell line. Molecular mechanisms and the influences of different regulation the expression of AKT1 on HCC cell growth, proliferation were determined by western blotting, MTT and colony formation assays, cell cycle and apoptosis were investigated by flow cytometry. The activation of AKT1 suppressed the expression of phosphatase and tensin homolog and increased the activation of Notch1. The inhibition of AKT1 effectively suppressed the expression of Notch1. Furthermore, the data of the present study indicated that B-cell lymphoma 2 and cyclin D1 is involved in the regulation of AKT1 expression.
\end{abstract}

\section{Introduction}

Primary liver cancer, which consists mainly of hepatocellular carcinoma (HCC), is the third-leading cause of cancer

Correspondence to: Professor Fangzhen Shen, Department of Oncology, Affiliated Hospital of Qingdao University, 16 Jiangsu Road, Qingdao, Shandong 266003, P.R. China

E-mail: shenfangzhen@163.com

Key words: hepatocellular carcinoma, $\mathrm{RAC}-\alpha$ serine/threonineprotein kinase, proliferation, phosphatase and tensin homolog, cell cycle, apoptosis, Notch1 mortality worldwide, following lung and stomach cancer, owing to its poor prognosis and frequent relapse and metastasis $(1,2)$. Although much is already known about the major pathogenic factors behind $\mathrm{HCC}$, including chronic hepatitis $\mathrm{B}$ and hepatitis $\mathrm{C}$ infection $(3,4)$, the definitive mechanisms behind HCC have not been elucidated. Only $30-40 \%$ of patients with HCC are eligible for potentially radical therapies (5), meaning the overall survival rate of patients with HCC remains low. Therefore, the identification of novel therapeutic targets to improve and develop treatment strategies for HCC.

The phosphoinositide 3-kinase (PI3K)/RAC seine/threonine-protein kinase (AKT)/mechanistic target of rapamycin (mTOR) signaling pathway is a promising therapeutic target owing to its frequent dysregulation in HCC and the critical functions it has in regulating cell survival, proliferation, apoptosis, migration and angiogenesis through phosphorylation of distinct protein substrates $(6,7)$. AKT is a key molecule in the $\mathrm{PI} 3 \mathrm{~K} / \mathrm{AKT} / \mathrm{mTOR}$ signaling pathway, which has been shown to serve notable functions in the regulation of cell viability and to be closely associated with a variety of disorders caused by dysfunctional cellular proliferation $(8,9)$. Three isoforms of AKT (AKT1, AKT2, and AKT3), which share $>80 \%$ sequence homology, have been identified in mammals $(10,11)$. It has been reported that overexpression of AKT is associated with decreased disease-free survival rates and development of primary carcinomas of the prostate, breast and ovary $(12,13)$. However, the action of individual AKT isoforms in different molecular subtypes of HCC has not been extensively evaluated. Lee et al (14) revealed that AKT1 serves a critical function in angiogenesis; AKT1 also has a crucial effect on cell survival (14-17). However, the precise molecular mechanisms by which AKT1 promotes cell proliferation and regulates apoptosis $(18,19)$ remain largely unclear.

High expression of activated AKT can be detected in HCC, and AKT may promote cell proliferation and regulation of cells apoptosis in HCC $(20,21)$. The present study confirmed a potential function for AKT1 in promoting proliferation and inhibiting apoptosis of HCC. Subsequent mechanism investigations revealed that AKT1 served a notable function in cell proliferation and anti-apoptosis by directly regulating the expression of phosphatase and tensin homolog (PTEN) and 
Notch1. The present study revealed that the specific inhibition of AKT1 may be therapeutically viable.

\section{Materials and methods}

Cell culture and plasmid transfection. The human HL-7702 and SMMC-7721 cell lines were purchased from the Shanghai Institutes for Biological Sciences (Chinese Academy of Science, Shanghai, China). HL-7702 and SMMC-7721 cells were cultured in RPMI-1640 medium (Gibco; Thermo Fisher Scientific, Inc., Waltham, MA, USA) supplemented with $10 \%$ fetal bovine serum containing penicillin $(100 \mathrm{U} / \mathrm{ml}) /$ streptomycin $(100 \mathrm{mg} / \mathrm{ml})$ (Gibco; Thermo Fisher Scientific, Inc.) and incubated at $37^{\circ} \mathrm{C}$ in a humidified atmosphere containing $5 \% \mathrm{CO}_{2}$. The pEGFP-N1-AKT1 plasmid was synthesized by Bioworld Technology, Inc. (St. Louis. Park, MN, USA). AKT1-RNAi plasmid was synthesized by Shanghai Genechem Co., Ltd. (Shangahi, China). A blank plasmid, an expression plasmid coding for AKT1-enhanced cyan fluorescent protein (pEGFP-N1-AKT1) and a plasmid containing short hairpin RNA (sh)-AKT (AKT1-RNAi plasmid) were transfected into cells using Effectene transfection reagent (Qiagen, Inc., Valencia, CA, USA), according to the manufacturer's protocol. SMMC-7721 cells were seeded into a 6-well plate ( $2 \times 10^{5}$ cells/well). Transfection was performed when the cell confluence reached $40-50 \%$ and cells were collected $48 \mathrm{~h}$ following transfection for subsequent experiments.

Reverse transcription-quantitative polymerase chain reaction (RT-qPCR) assay. Total RNA was extracted from HCC cells with TRIzol (Thermo Fisher Scientific, Inc.). RNA was reverse-transcribed into cDNA using a PrimeScript RT reagent kit (Takara Bio, Inc.). cDNA samples were subjected to qPCR using the SYBR Premix Ex Taq kit (Takara Bio, Inc.). The thermocycling conditions were as follows: 40 cycles of pre-denaturation at $95^{\circ} \mathrm{C}$ for $30 \mathrm{sec}$, annealing at $95^{\circ} \mathrm{C}$ for $5 \mathrm{sec}$ and final extension at $60^{\circ} \mathrm{C}$ for $30 \mathrm{sec}$. Relative gene expression data were calculated using the $2^{-\Delta \Delta \mathrm{Cq}}$ method (22). All reactions were performed in triplicate and all experiments were performed three times. GAPDH was used as a reference gene. The primers are presented in Table I.

Western blot analysis. SMMC-7721 cells were transfected with the pEGFP-N1-AKT1, AKT1-RNAi and blank plasmids for $48 \mathrm{~h}$. SMMC-7721 cells were lysed using radioimmunoprecipitation assay buffer (Beyotime Institute of Biotechnology, Haimen, China). The protein concentration was determined using a bicinchoninic acid assay kit (Beyotime Institute of Biotechnology). A total of $20 \mu \mathrm{g}$ protein was separated by SDS-PAGE (10\% gel) and transferred onto polyvinylidene fluoride membranes. Following blocking with 5\% skimmed milk for $2 \mathrm{~h}$ at room temperature, membranes were incubated with primary antibodies at $4^{\circ} \mathrm{C}$ overnight. Primary antibodies included: Anti AKT1 (rabbit monoclonal; dilution, 1:1,000; cat no. 2938), PTEN (mouse monoclonal; dilution, 1:1,000; cat no. 9556), Notch1 (rabbit monoclonal; dilution, 1:1,000; cat no. 3608), cyclin D1 (rabbit monoclonal; dilution, 1:1,000; cat no. 2922), Bcl2 (rabbit monoclonal; dilution, 1:1,000; cat no. 3498), GAPDH (rabbit monoclonal; dilution, 1:1,000; cat no. 5174) (all primary antibodies from Cell Signaling
Technology, Inc., Danvers, MA, USA). The membrane was washed three times with Tris-buffered saline with $0.1 \%$ Tween-20 (TBST) for $15 \mathrm{~min}$ three times, then incubated with anti-rabbit $(1: 10,000$; cat no. 7074 ; Cell Signaling Technology, Inc.) or anti-mouse (1:10,000; cat no. 7076; Cell Signaling Technology, Inc.) secondary antibodies for $2 \mathrm{~h}$ at room temperature. The protein bands were visualized using enhanced chemiluminescence (ECL Plus kit; Thermo Fisher Scientific, Inc.). The protein expression was detected using Image-Pro Plus software (version 6.0; Media Cybernetics, Inc., Rockville, MD, USA).

Colony forming assay. For the colony forming assay, 2,000 cells in the blank plasmid, pEGFP-N1-AKT1 plasmid and AKT1-RNAi plasmid transfection groups were added to a 6-well plate and incubated in a humid incubator at $37^{\circ} \mathrm{C}$ with $5 \% \mathrm{CO}_{2}$. After 10 days in culture, cells were fixed with $100 \%$ methanol for $30 \mathrm{~min}$ at room temperature and stained with $0.2 \%$ crystal violet for $15 \mathrm{~min}$ at room temperature. Colonies ( $>50$ cells) were then counted using light microscopy (magnification, $\mathrm{x} 40$ ).

MTT cell proliferation assay. For the MTT assay, SMMC-7721 cells were seeded into a 96 -well plate $(6,000$ cells/well), incubated for $24 \mathrm{~h}$, and separately transfected with blank plasmid, pEGFP-N1-AKT1 plasmid or AKT1-RNAi plasmid for $48 \mathrm{~h}$. Once the medium was replaced with $100 \mu 1$ culture liquid containing $10 \%$ fetal bovine serum, $20 \mu \mathrm{l}$ MTT solution was added and plates were incubated for another $4 \mathrm{~h}$, followed by the addition of $150 \mu 1$ dimethyl sulfoxide. The absorbance was measured at $490 \mathrm{~nm}$ using a microplate reader to determine the number of viable cells in each well.

Flow cytometric analysis. SMMC-7721 cells were seeded into 6-well plates for $\sim 12 \mathrm{~h}$ until confluence reached $50 \%$. Next, cells were transfected with blank, pEGFP-N1-AKT1 or AKT1-RNAi plasmids, as aforementioned. After $48 \mathrm{~h}$, cells were washed with ice-cold PBS and fixed with $70 \%$ ice-cold ethanol at $4^{\circ} \mathrm{C}$ overnight. Subsequently, propidium iodide (PI; Beyotime Institute of Biotechnology) was added to transfected cells for $30 \mathrm{~min}$ at $4^{\circ} \mathrm{C}$ in the dark. Finally, an Aria II flow cytometer (BD Biosciences, Franklin Lakes, NJ, USA) was used to detect the distribution of cells in the cell cycle. The proportion of cells in different phrases was analyzed using FlowJo software (version 7.6; FlowJo LLC, Ashland, OR, USA).

Analysis of apoptosis. At $48 \mathrm{~h}$ post-transfection, SMMC-7721 cells were suspended in binding buffer and were hatched with an Annexin-V-fluorescein isothiocyanate (FITC)/PI apoptosis detection kit (Beyotime Institute of Biotechnology) for $30 \mathrm{~min}$ at room temperature in the dark. Flow cytometry was performed using a flow cytometer. The results were analyzed using FlowJo software (version 7.6; FlowJo LLC, Ashland, OR, USA).

Statistical analysis. Student's t-test or one-way ANOVA followed by least significant difference or Dunnett's test. Statistical analyses were conducted using GraphPad Prism 6 (GraphPad Software, Inc., La Jolla, CA, USA) and PASW Statistics 18 (SPSS, Inc., Chicago, IL, USA). Results are presented as the mean \pm standard error of the mean. $\mathrm{P}<0.05$ 
Table I. Reverse transcription-quantitative polymerase chain reaction primers.

\begin{tabular}{lc}
\hline Gene & Sequence \\
\hline AKT1 & \\
Forward & 5'-CACAAACGAGGGGAGTACATC-3' \\
Reverse & 5'-GCCATCATTCTTGAGGAGGAAGT-3' \\
PTEN & \\
Forward & 5'-AGGGACGAACTGGTGTAATGA-3' \\
Reverse & 5'-CTGGTCCTTACTTCCCCATAGAA-3' \\
Notch1 & \\
Forward & 5'-ACTGTGTAGGACCTGGTGGAC-3' \\
Reverse & 5'-TTGTAGGTGTTGGGGAGGTC-3' \\
GAPDH & \\
Forward & 5'-TCATGGGTGTGAACCATGAGAA-3' \\
Reverse & 5'-GGCATGGACTGTGGTCATGAG-3'
\end{tabular}

AKT1, RAC- $\alpha$ serine/threonine-protein kinase; PTEN, phosphatase and tensin homolog.

was considered to indicate a statistically significant difference. All experiments were performed in triplicate.

\section{Results}

Expression of AKT1 is upregulated in HCC. Western blot analysis and RT-qPCR were used to examine the expression levels of AKT1 in HCC SMMC-7721 cell line, as compared with the expression level in normal liver cell line HL-7702. The results demonstrated that AKT1 was significantly upregulated in SMMC-7721 cells ( $\mathrm{P}<0.05$; Fig. 1A and B). As AKT1 expression was elevated in HCC cells, AKT1 appears to have a positive effect on HCC progression. The transfection efficiency of various plasmids [blank plasmid, AKT1-upregulation plasmid (pEGFP-N1-AKT1 plasmid) and AKT1-downregulation plasmid (AKT1-RNAi plasmid)] was then assessed. Transfection with the AKT1-upregulation plasmid promoted the expression of AKT1 and AKT-1-downregulation plasmid inhibited the expression of AKT1 $(\mathrm{P}<0.05$; Fig. 2A and B).

Upregulation of AKT1 promotes HCC cell proliferation, whereas downregulation of $A K T 1$ inhibits proliferation. To identify the function of AKT1 in HCC progression,SMMC-7721 cells were transfected with pEGFP-N1-AKT1 or AKT1-RNAi plasmids. The expression of AKT1 protein in pEGFP-N1-AKT1 plasmid-transfected cells was upregulated by $150-300 \%$, whereas in AKT1-RNAi plasmid-transfected cells it was downregulated by 400-1,000\%, compared with cells transfected with an empty vector $(\mathrm{P}<0.05$; Fig. $2 \mathrm{~A}$ and $\mathrm{B})$. The transfection efficiency was confirmed by RT-qPCR and western blot analysis.

MTT and colony formation assays were performed to assess the function of AKT1 on HCC cell proliferation. These assays revealed that the overexpression of AKT1 resulted in a significant increase in viability compared with control group in SMMC-7721 cells. In line with this, downregulation of
AKT1 suppressed cell proliferation ( $\mathrm{P}<0.05$; Fig. $3 \mathrm{~A}$ and $\mathrm{B})$. These results demonstrated that AKT1 effectively promoted the proliferation of HCC cells, whereas knockdown of AKT1 inhibited proliferation. These results indicate that the upregulation of AKT1 expression promoted cell proliferation, whereas its downregulation restrained this proliferation.

Deactivation of AKT1 suppresses cell cycle and induces apoptosis in HCC cells. Suppression of AKT1 in SMMC-7721 by transfection with the AKT1-RNAi plasmid confirmed the function of AKT1 in HCC cells. Flow cytometric analysis revealed a marked increase in the percentage of cells at $\mathrm{G}_{1} / \mathrm{G}_{0}$ phase and a decrease in the percentage of cells in $S$ phase in the AKT1-RNAi plasmid transfected cells, compared with those transfected with the blank vector $(\mathrm{P}<0.05$; Fig. 4A). Furthermore, inhibition of AKT1 led to a decrease in B-cell lymphoma-2 (Bcl-2) and cyclin $\mathrm{D} 1$ expression $(\mathrm{P}<0.05$; Fig. 5A). Subsequently, apoptosis analysis using flow cytometry an increase in the percentage of annexin V-FITC-positive HCC cells in those transfected with AKT1-RNAi compared with the control cells $(\mathrm{P}<0.05$; Fig. 4B). These results demonstrated that inhibition of AKT1 suppresses the cell cycle in HCC cells and promotes apoptosis.

AKT1 promotes HCC cell survival and proliferation by targeting PTEN in vivo. PTEN is a dual lipid/protein phosphatase, acting as a tumor suppressor by negatively regulating the AKT signaling pathway; it is inactivated in a number of cancer types $(23,24)$. PTEN is crucial for inhibiting cell proliferation downstream of Notch (25-27). The upregulation of Notch1 in SMMC-7721 cells increased the expression of Notch1 compared with that in control cells. The RT-qPCR and western blot assays were additionally performed to examine the effects of AKT1 on the endogenous expression of PTEN and Notch1. As shown in Fig. 5, AKT1 downregulation was associated with a significant increase and decrease in PTEN and Notch1 mRNA and protein levels, respectively, in SMMC-7721 cells, with AKT1 overexpression inducing the opposite result. It is possible that Notch1 and PI3K-AKT signaling are closely linked to the control of cell growth and proliferation via PTEN and differential regulation of AKT1 signaling promotes cell growth, in part through Notch1.

\section{Discussion}

$\mathrm{HCC}$ is one of the most common malignant tumors of digestive tract carcinoma, the incidence of which has been increasing recently (28-31). The survival rate and prognosis of patients with $\mathrm{HCC}$ are poor, partly owing to local recurrence, metastasis and multi-drug resistance of tumor cells $(32,33)$. Furthermore, HCC is refractory to treatment as it is usually diagnosed at advanced stages (34). Accordingly, it is necessary to seek novel therapeutic targets for the treatment of HCC. The present study investigated the link between AKT1 and HCC and assessed the effect of differential regulation of AKT1 on the proliferation and apoptosis of cells and the specific regulatory mechanisms involved. Previous studies have indicated that AKT is closely associated with cell survival, proliferation, apoptosis, migration and angiogenesis in $\operatorname{HCC}(6,17)$. AKT was frequently dysregulated in hepatoma cell lines and human 
A

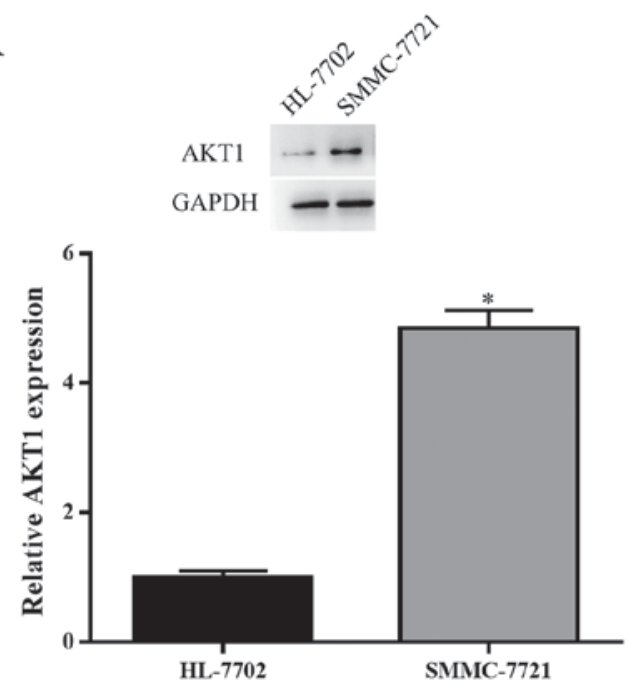

B

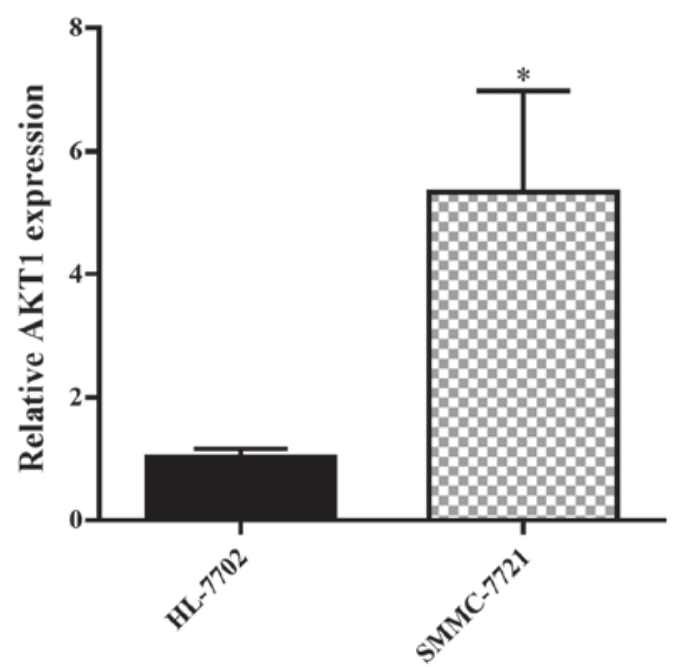

Figure 1. (A) Western blotting and (B) reverse transcription-quantitative polymerase chain reaction analysis revealed that the AKT1 over expression in the hepatocellular carcinoma SMMC-7721 cell line compared to the normal liver HL-7702 cell line. Results are presented as the mean \pm standard error of the mean for three independent experiments. ${ }^{*} \mathrm{P}<0.05$. AKT1, RAC- $\alpha$ serine/threonine-protein kinase.

A



B Blank
pEGFP-N1-AKT 1

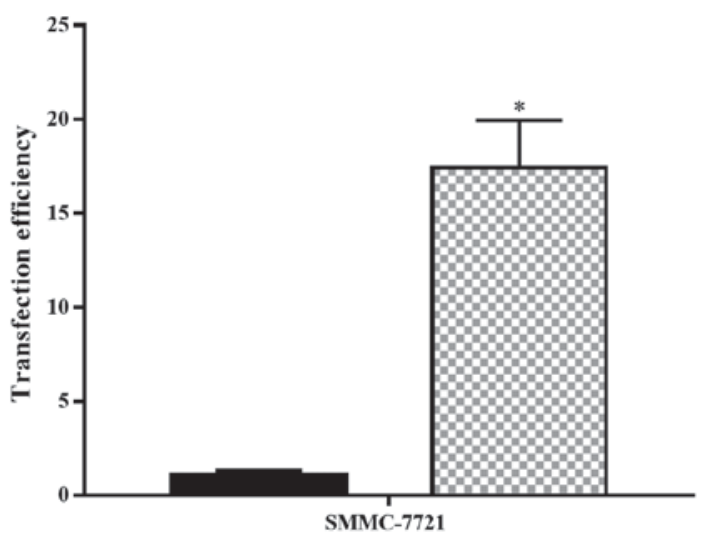

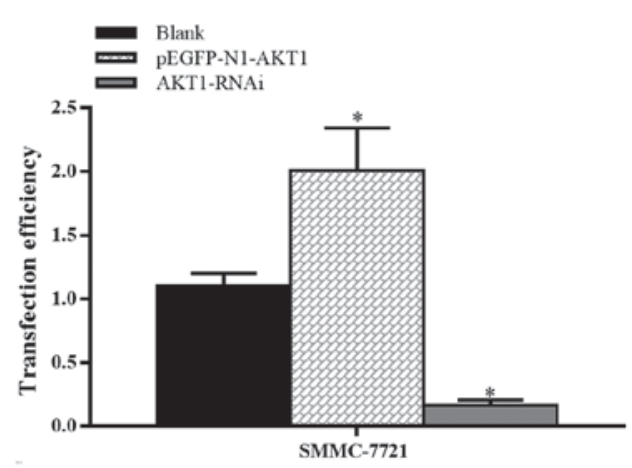

Blank

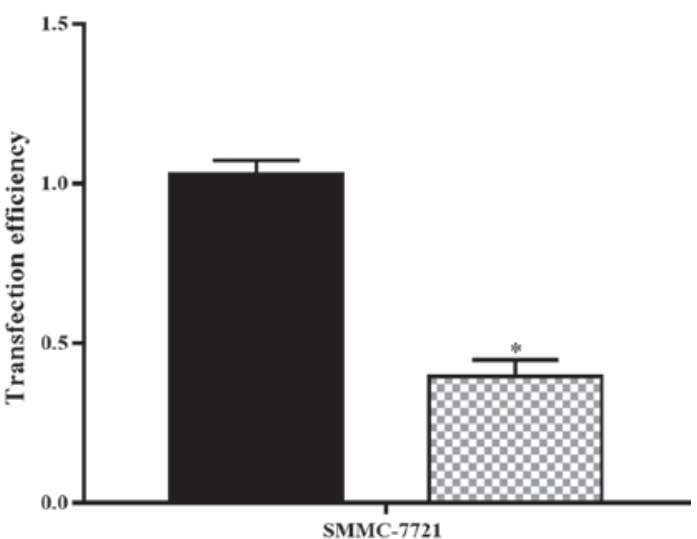

Figure 2. Transfection efficiency was evaluated using western blot analysis (A) and (B) the reverse transcription-quantitative polymerase chain reaction. Transfection with pEGFP-N1-AKT1 plasmid increases AKT1, whereas transfected with AKT1-RNAi decreases AKT expression. Results are presented as the mean \pm standard error of the mean for three independent experiments. ${ }^{*} \mathrm{P}<0.05$. AKT1, RAC- $\alpha$ serine/threonine-protein kinase; RNAi, RNA interference.

HCC tissues (35). AKT isoforms are highly expressed in the majority of cancer types, including those of the lung, breast and colon, and $\mathrm{HCC}$; however, the isoform-specific functions in the occurrence and development of HCC remain unclear. 
A

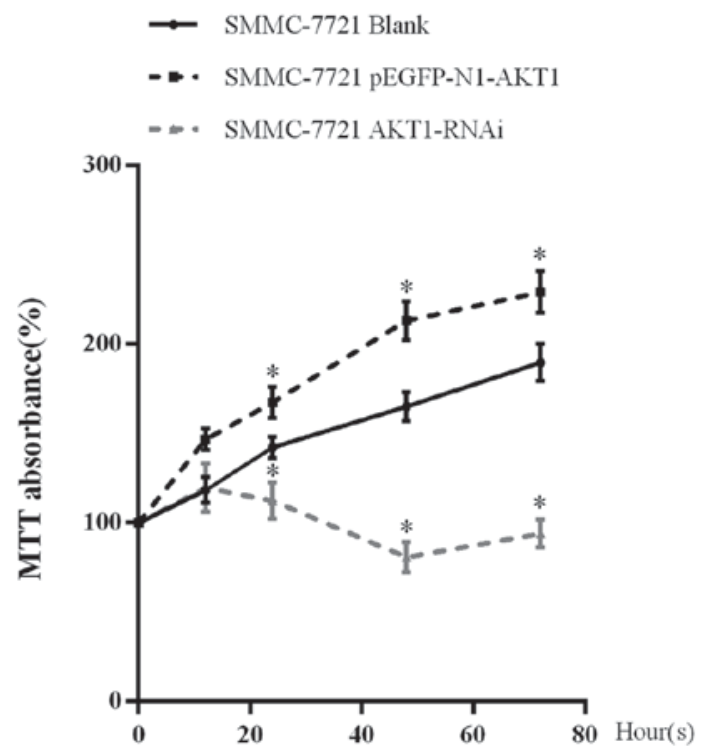

B


Figure 3. SMMC-7721 cells were treated with blank plasmid, pEGFP-N1-AKT1 plasmid and AKT1-RNAi plasmid. The cell proliferation was determined using an MTT assay and the colony formation assay. The effect of AKT1 on cell viability following transfection at different time points (12, 24, 48 and 72 h) was measured. (A) Cell viability was determined using an MTT assay. (B) A colony formation assay was performed to further investigate the effects of AKT1 on the cell proliferative capacity in SMMC-7721 cells. Increased expression of AKT1 is able to accelerate cell growth, whereas downregulation of AKT1 inhibits cell proliferation in SMMC-7721 cells. Results are presented as the mean \pm standard error of the mean for three independent experiments. ${ }^{*}<0.05$ vs. blank. AKT1, RAC- $\alpha$ serine/threonine-protein kinase; RNAi, RNA interference.

A

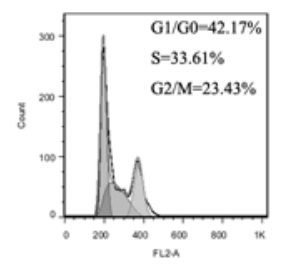

SMMC-7721 Blank

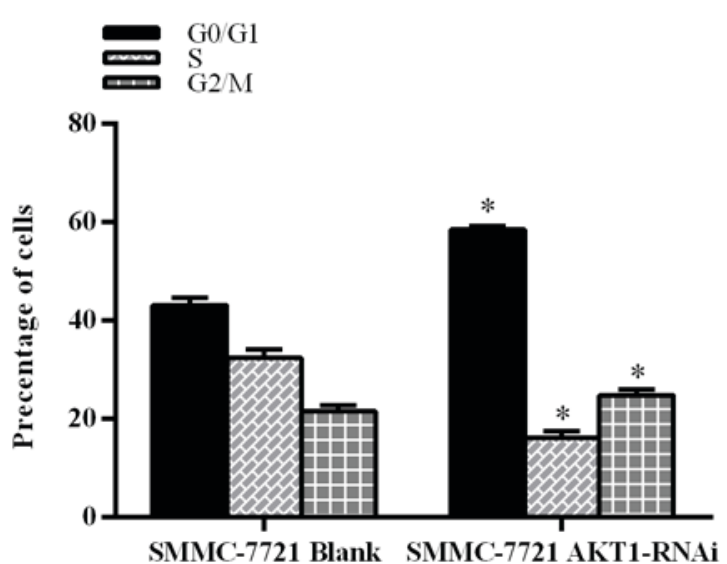

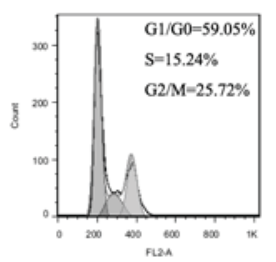

SMMC-7721 AKT1-RNAi

B

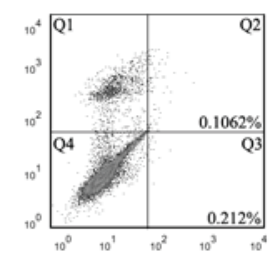

SMMC-7721 Blank

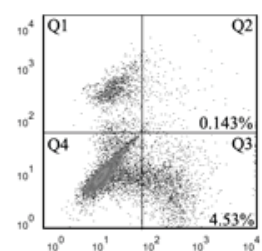

SMMC-7721 AKT1-RNAi

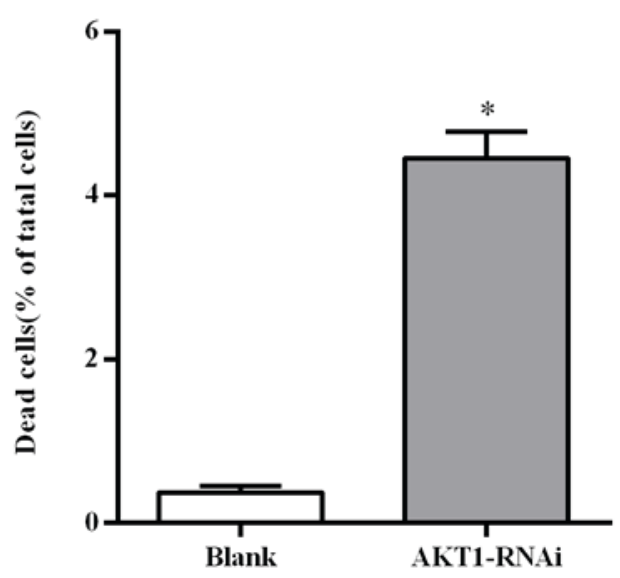

Figure 4. Effects of silencing AKT1 expression on cell cycle progression in SMMC-7721 cells. Cells were analyzed by flow cytometry following staining with propidium iodide. (A) The histogram depicts the percentage of all stages in each cell cycle phase. P<0.05. (B) AKT1 deficiency induces SMMC-7721 cells apoptosis. Following transfection with the indicated plasmid for $48 \mathrm{~h}$, the percentage of apoptotic cells were determined using flow cytometric analysis. Each quadrant represents viable cells (lower left), early apoptotic cells (lower right), late or secondary necrotic cells (upper right), and primary necrotic cells (upper left). Downregulation of AKT1 promotes cell apoptosis in the SMMC-7721 cell line compared with the blank control. Results are presented as the mean \pm standard error of the mean for three independent experiments. ${ }^{*} \mathrm{P}<0.05$. AKT1, RAC- $\alpha$ serine/threonine-protein kinase; RNAi, RNA interference.

As a member of the AKT family, AKT1 expression has been proved to be dysregulated in cancer cells; this dysregulation of AKT1 is associated with cancer cell survival, proliferation and metabolism $(15,16)$. Previous evidence demonstrated that 


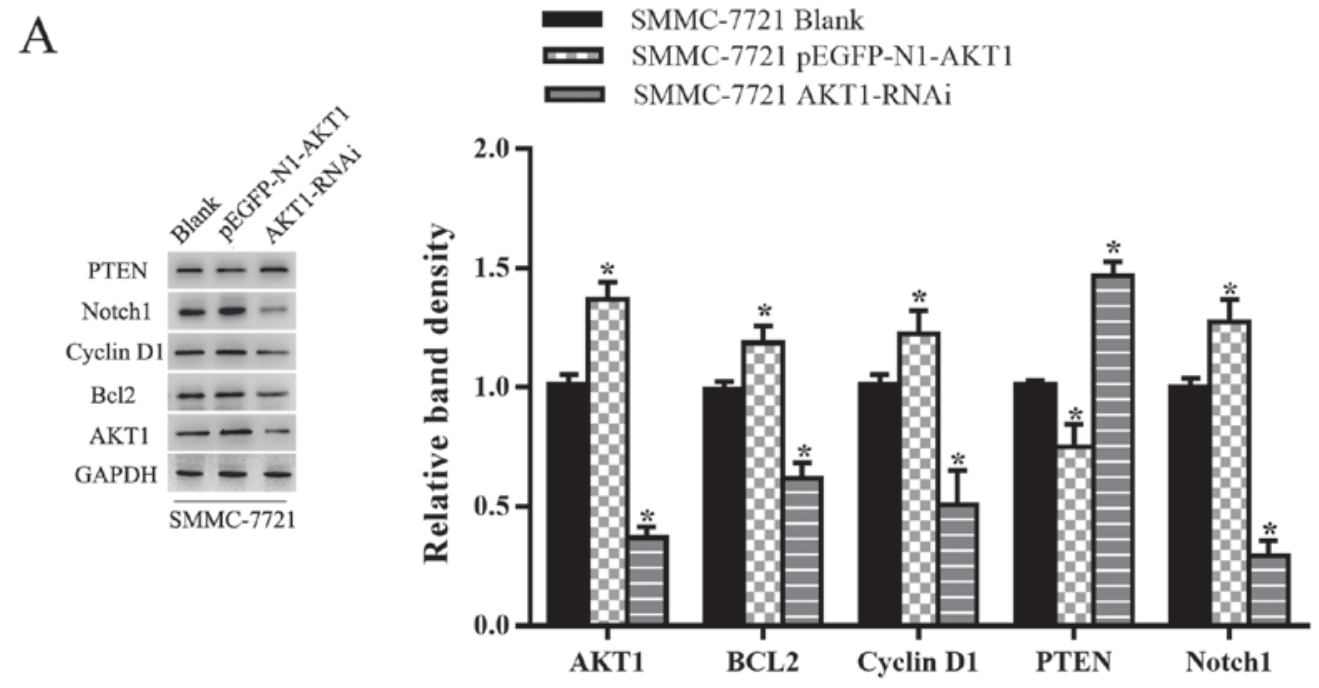

B

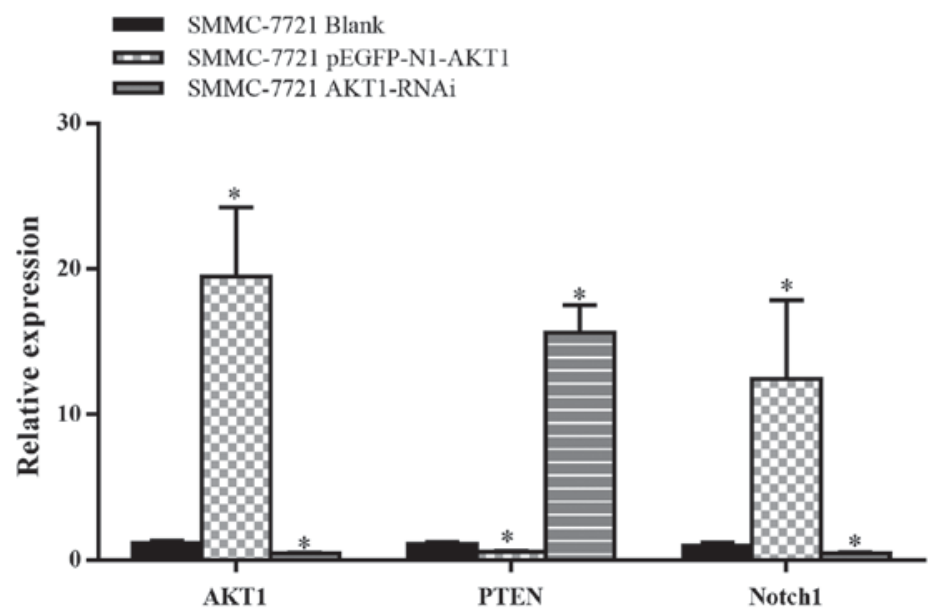

Figure 5. (A) Western blotting analysis and (B) reverse transcription-quantitative polymerase chain reaction assay of PTEN, Notch1, Bcl-2, cyclin D1 expression in AKT1-overexpressing, and knockdown cells compared with blank control. Notch1, Bcl-2 and cyclin D1 expression are positively regulated by AKT1 and PTEN is negatively regulated by AKT1. Results are presented as the mean \pm standard error of the mean for three independent experiments. "P $<0.05$ vs. blank. PTEN, phosphatase and tensin homolog; Bcl-2, B-cell lymphoma 2; AKT1, RAC- $\alpha$ serine/threonine-protein kinase; RNAi, RNA interference.

AKT1 participates in the initiation, progression and metastasis of malignant tumors (36-38). Thus, AKT1 has emerged as a novel potential target of anticancer drugs.

The present study analyzed the functional relevance of AKT1 action on the HCC SMMC-7721 cell line, on proliferation, apoptosis and cell cycle. First, the AKT1 expression in different HCC subtypes was screened and found that AKT1 was high expression in SMMC-7721 HCC cell line. Compared with the HCC, the expression of AKT1 was higher in SMMC-7721 cells. This result is in line with that of a previous study showing that AKT was high expression in oncological patients $(38,39)$. To identify the precise impact of AKT1 on the occurrence and development of HCC, colony formation, MTT, and flow cytometry assays were performed. The results of these analyses demonstrated that AKT1 had significant impact on cellular survival and proliferation. Silencing AKT1 significantly stimulated apoptosis and suppressed the cell cycle, whereas increasing AKT1 expression promoted HCC cells proliferation.

To investigate the mechanism of action of AKT1 in HCC, we increased and decreased AKT1 expression levels in HCC cell lines using the pEGFP-N1-AKT1 and AKT1-RNAi plasmids, respectively. Compared with the control, the level of AKT1 expression was significantly enhanced in pEGFP-N1-AKT1 plasmid-transfected cells and significantly decreased in cells transfected with the AKT1-RNAi plasmid. When the AKT1-RNAi plasmid was transfected into the HCC cell line, PTEN expression was significantly increased and Notch1 was evidently decreased, indicating that that PTEN and Notch1 may be the target of AKT1 in HCC cells. Recent studies have shown that Notch1 inhibits HCC through the upregulation of PTEN and the subsequent inactivation of focal adhesion kinase; PTEN is a phosphatase that can negatively regulate Notch $(25,40)$. The expression of AKT1, which is negatively associated with PTEN expression, was positively associated with Notch1 expression in AKT1-RNAi plasmid-transfected cells. Additionally, the pEGFP-N1-AKT1 plasmid-transfected cells were in the opposite direction. In addition, the present study revealed that the downregulation of AKT1 expression in the HCC SMMC-7721 cell line by transfection with the AKT1-RNAi plasmid suppressed cell survival and proliferation, and promoted apoptosis. 
Previous studies revealed that the Notch 1 and the PI3K/AKT signaling pathways interact in more complex signaling networks, centered on one of the principal downstream targets of Notch1 $(41,42)$. PTEN protein is a tumor suppressor gene that is mutated in a large number of cancer types at high frequency (43-46). Notch1 negatively regulates PTEN at the transcriptional level (47). The Notch signaling pathway, a highly conserved pathway composed of Notch1-4 receptors (48), is critical for a wide variety of cells and tissues through its regulation of growth, differentiation and apoptosis. Notch1 is a receptor that tends to be highly expressed in human HCC (40). In the present study, RT-qPCR and western blot analysis revealed that Notch1 acted as a tumor promoter by modulating the PI3K/AKT pathway in HCC, and that PTEN is a possible intermediary of this signaling. The downregulation of AKT1 by the AKT1-RNAi plasmid in SMMC-7721 cells increased PTEN expression and decreased the expression of Notch1. These results contributed to cell apoptosis, increasing the expression of Bcl-2 and reducing the expression of cyclin D1, inducing $G_{1}$ cell cycle arrest. AKT1 overexpression elicited an opposite effect to AKT1 knockdown. PTEN expression appears to serve a notable function in restraining the proliferation of HCC in AKT1.

In conclusion, the results of the present study indicated that silencing AKT1 is highly effective in upregulating expression of the tumor-suppressing gene PTEN and reducing expression of Notch1 expression, dampening tumor growth and inducing apoptosis. Targeting AKT1 suppresses HCC growth and provides a basis for designing novel therapeutic strategies for HCC.

\section{Competing interests}

The authors declare that they have no competing interests.

\section{References}

1. Ferenci P, Fried M, Labrecque D, Bruix J, Sherman M, Omata M, Heathcote J, Piratsivuth T, Kew M, Otegbayo JA, et al: Hepatocellular carcinoma (HCC): A global perspective. J Clin Gastroenterol 44: 239-245, 2010.

2. El-Serag HB and Rudolph KL: Hepatocellular carcinoma: Epidemiology and molecularcarcinogenesis. Gastroenterology 132: 2557-2576, 2007.

3. Li J, Wang K, Chen X, Meng H, Song M, Wang Y, Xu X and Bai Y: Transcriptional activation of microRNA-34a by NF-kappa B in human esophageal cancer cells. BMC Mol Biol 13: 4, 2012.

4. Gupta P, Cairns MJ and Saksena NK: Regulation of gene expression by microRNA in $\mathrm{HCV}$ infection and $\mathrm{HCV}$-mediated hepatocellular carcinoma. Virol J 11: 64, 2014.

5. Enguita-Germán M and Fortes P: Targeting the insulin-like growth factor pathway in hepatocellular carcinoma. World J Hepatol 6: 716-737, 2014.

6. Bhaskar PT and Hay N: The two TORCs and Akt. Dev Cell 12: 487-502, 2007

7. Engelman JA: Targeting PI3K signalling in cancer: Opportunities, challenges and limitations. Nat Rev Cancer 9: 550-562, 2009.

8. Toker A and Yoeli-Lerner M: Akt signaling and cancer: Surviving but not moving on. Cancer Res 66: 3963-3966, 2006.

9. Fresno Vara JA, Casado E, de Castro J, Cejas P, Belda-Iniesta C and González-Barón M: PI3K/Akt signalling pathway and cancer. Cancer Treat Rev 30: 193-204, 2004.

10. Brodbeck D, Hill MM and Hemmings BA: Two splice variants of protein kinase B gamma have different regulatory capacity depending on the presence or absence of the regulatory phosphorylation site serine 472 in the carboxylterminal hydrophobic domain. J Biol Chem 276: 29550-29558, 2001.
11. Brodbeck D, Cron P and Hemmings BA: A human protein kinase Bgamma with regulatory phosphorylation sites in the activation loop and in the C-terminal hydrophobic domain. J Biol Chem 274: 9133-9136, 1999.

12. Grottke A, Ewald F, Lange T, Nörz D, Herzberger C, Bach J, Grabinski N, Gräser L, Höppner F, Nashan B, et al: Downregulation of AKT3 increases migration and metastasis in triple negative breast cancer cells by upregulating S100A4. PLoS One 11: e0146370, 2016.

13. Sun M, Wang G, Paciga JE, Feldman RI, Yuan ZQ, Ma XL, Shelley SA, Jove R, Tsichlis PN, Nicosia SV and Cheng JQ: $\mathrm{AKT1} / \mathrm{PKBalpha}$ kinase is frequently elevated in human cancers and its constitutive activation is required for oncogenic transformation in NIH3T3 cells. Am J Pathol 159: 431-437, 2001.

14. Lee MY, Luciano AK, Ackah E, Rodriguez-Vita J, Bancroft TA, Eichmann A, Simons M, Kyriakides TR, Morales-Ruiz M and Sessa WC: Endothelial Akt1 mediates angiogenesis by phosphorylating multiple angiogenic substrates. Proc Natl Acad Sci U S A 111: 12865-12870, 2014.

15. Chen WS, Xu PZ, Gottlob K, Chen ML, Sokol K, Shiyanova T, RoninsonI,Weng W,Suzuki R, Tobe K, et al: Growth retardation and increased apoptosis in mice with homozygous disruption of the Akt1 gene. Genes Dev 15: 2203-2208, 2001.

16. Cho H, Thorvaldsen JL, Chu Q, Feng F and Birnbaum MJ: Akt1/PKBalpha is required for normal growth but dispensable for maintenance of glucose homeostasis in mice. J Biol Chem 276: 38349-38352, 2001.

17. Xu N, Lao Y, Zhang Y and Gillespie DA: Akt: A double-edged sword in cell proliferation and genome stability. J Oncol 2012: 951724, 2012.

18. Yu Z, Xu Z, Disante G, Wright J, Wang M, Li Y, Zhao Q, Ren T, Ju X, Gutman E, et al: miR-17/20 sensitization of breast cancer cells to chemotherapy-induced apoptosis requires Akt1. Oncotarget 5: 1083-1090, 2014.

19. Green BD, Jabbour AM, Sandow JJ, Riffkin CD, Masouras D, Daunt CP, Salmanidis M, Brumatti G, Hemmings BA, Guthridge MA, et al: Akt1 is the principal Akt isoform regulating apoptosis in limiting cytokine concentrations. Cell Death Differ 20: 1341-1349, 2013.

20. Ewald F, Nörz D, Grottke A, Bach J, Herzberger C, Hofmann BT Nashan B and Jücker M: Vertical targeting of AKT and mTOR as well as dual targeting of AKT and MEK signaling is synergistic in hepatocellular carcinoma. J Cancer 6: 1195-1205, 2015.

21. Chen WS, Xu PZ, Gottlob K, Chen ML, Sokol K, Shiyanova T, Roninson I, Weng W, Suzuki R, Tobe K, et al: Growth retardation and increased apoptosis in mice with homozygous disruption of the akt1 gene. Genes Dev 15: 2203-2208, 2001.

22. Livak KJ and Schmittgen TD: Analysis of relative gene expression data using real-time quantitative PCR and the 2(-Delta Delta C (T)) method. Methods 25: 402-408, 2001.

23. Lee MS, Jeong MH, Lee HW, Han HJ, Ko A, Hewitt SM, Kim JH, Chun KH, Chung JY, Lee C, et al: PI3K/AKT activation induces PTEN ubiquitination and destabilization accelerating tumourigenesis. Nat Commun 6: 7769, 2015.

24. He X, Saji M, Radhakrishnan D, Romigh T, Ngeow J, Yu Q, Wang Y, Ringel MD and Eng C: PTEN lipid phosphatase activity and proper subcellular localization are necessary and sufficient for down-regulating AKT phosphorylation in the nucleus in cowden syndrome. J Clin Endocrinol Metab 97: E2179-E2187, 2012.

25. Serra H, Chivite I, Angulo-Urarte A, Soler A, Sutherland JD, Arruabarrena-Aristorena A, Ragab A, Lim R, Malumbres M, Fruttiger M, et al: PTEN mediates Notch-dependent stalk cell arrest in angiogenesis. Nat Commun 6: 7935, 2015.

26. Jo HS, Kang KH, Joe CO and Kim JW: Pten coordinates retinal neurogenesis by regulating Notch signaling. EMBO J 31: 817-828, 2012.

27. Vo K, Amarasinghe B, Washington K, Gonzalez A, Berlin J and Dang TP: Targeting notch pathway enhances rapamycin antitumor activity in pancreas cancers through PTEN phosphorylation. Mol Cancer 10: 138, 2011.

28. Bosch FX, Ribes J, Díaz M and Cléries R: Primary liver cancer: Worldwide incidence and trends. Gastroenterology 127: S5-S16, 2004.

29. Parkin DM, Bray F, Ferlay J and Pisani P: Global cancer statistics, 2002. CA Cancer J Clin 55: 74-108, 2005.

30. Torre LA, Bray F, Siegel RL, Ferlay J, Lortet-Tieulent J and Jemal A: Global cancer statistics, 2012. CA Cancer J Clin 65: 87-108, 2015. 
31. Siegel RL, Miller KD and Jemal A: Cancer statistics CA Cancer J Clin 65: 5-29, 2015.

32. Luo G, Chao YL, Tang B, Li BS, Xiao YF, Xie R, Wang SM, Wu YY, Dong H, Liu XD and Yang SM: miR-149 represses metastasis of hepatocellular carcinoma by targeting actin-regulatory proteins PPM1F. Oncotarget 6: 37808-37823, 2015.

33. Chow AK, Ng L, Lam CS, Wong SK, Wan TM, Cheng NS, Yau TC, Poon RT and Pang RW: The enhanced metastatic potential of hepatocellular carcinoma (HCC) cells with sorafenib resistance. PLoS One 8: e78675, 2013.

34. Llovet JM, Fuster J and Bruix J: The Barcelona approach: Diagnosis, staging, and treatment of hepatocellular carcinoma. Liver Transpl 10: S115-120, 2004.

35. Chen JS, Wang Q, Fu XH, Huang XH, Chen XL, Cao LQ, Chen LZ, Tan HX, Li W, Bi J and Zhang LJ: Involvement of $\mathrm{PI} 3 \mathrm{~K} / \mathrm{PTEN} / \mathrm{AKT} / \mathrm{mTOR}$ pathway in invasion and metastasis in hepatocellular carcinoma: Association with MMP-9. Hepatol Res 39: 177-186, 2009.

36. Bellacosa A, Testa JR, Staal SP and Tsichlis PN: A retroviral oncogene, akt, encoding a serine-threonine kinase containing an SH2-like region. Science 254: 274-277, 1991.

37. Bellacosa A, Franke TF, Gonzalez-Portal ME, Datta K, Taguchi T, Gardner J, Cheng JQ, Testa JR and Tsichlis PN: Structure, expression and chromosomal mapping of c-akt: Relationship to v-akt and its implications. Oncogene 8: 745-754, 1993.

38. Yang ZZ, Tschopp O, Hemmings-Mieszczak M, Feng J Brodbeck D, Perentes E and Hemmings BA: Protein kinase B alpha/Akt1 regulates placental development and fetal growth. J Biol Chem 278: 32124-32131, 2003.

39. Skeen JE, Bhaskar PT, Chen CC, Chen WS, Peng XD, Nogueira V, Hahn-Windgassen A, Kiyokawa $\mathrm{H}$ and Hay N: Akt deficiency impairs normal cell proliferation and suppresses oncogenesis in a p53-independent and mTORC1-dependent manner. Cancer Cell 10: 269-280, 2006.

40. Hu YJ, Li HY, Qiu KJ, Li DC, Zhou JH, Hu YH and Zhang FM: Downregulation of Notch1 inhibits the invasion of human hepatocellular carcinoma HepG2 and MHCC97H cells through the regulation of PTEN and FAK. Int J Mol Med 34: 1081-1086, 2014.
41. Zhou W, Fu XQ, Zhang LL, Zhang J, Huang X, Lu XH, Shen L, Liu BN,Liu J,LuoHS, et al:The AKT1/NF-kappaB/Notch1/PTEN axis has an important role in chemoresistance of gastric cancer cells. Cell Death Dis 4: e847, 2013.

42. Hales EC, Orr SM, Larson Gedman A, Taub JW and Matherly LH: Notch1 Receptor Regulates AKT protein activation loop (Thr308) dephosphorylation through modulation of the PP2A Phosphatase in phosphatase and tensin homolog (PTEN)-null T-cell acute lymphoblasticleukemiacells.JBiolChem288: 22836-22848,2013.

43. Wang L, Wang WL, Zhang Y, Guo SP, Zhang J and Li QL: Epigenetic and genetic alterations of PTEN in hepatocellular carcinoma. Hepatol Res 37: 389-396, 2007.

44. Chow LM and Baker SJ: PTEN function in normal and neoplastic growth. Cancer Lett 241: 184-196, 2006.

45. Hu TH, Huang CC, Lin PR, Chang HW, Ger LP, Lin YW, Changchien CS, Lee CM and Tai MH: Expression and prognostic role of tumor suppressor gene PTEN/MMAC1/TEP1 in hepatocellular carcinoma. Cancer 97: 1929-1940, 2003

46. Dong-Dong L, Xi-Ran Z and Xiang-Rong C: Expression and significance of new tumor suppressor gene PTEN in primary liver cancer. J Cell Mol Med 7: 67-71, 2003.

47. Palomero T, Sulis ML, Cortina M, Real PJ, Barnes K, Ciofani M, Caparros E, Buteau J, Brown K, Perkins SL, et al: Mutational loss of PTEN induces resistance to NOTCH1 inhibition in T-cell leukemia. Nat Med 13: 1203-1210, 2007.

48. Miele L, Miao H and Nickoloff BJ: NOTCH signaling as a novel cancer therapeutic target. Curr Cancer Drug Targets 6: 313-323, 2006. 